\title{
GRUZINSKI, Serge, Las cuatro partes del mundo. Historia de una mundialización, Fondo de Cultura Económica, México, 2010, 480 páginas
}

Este libro, publicado originalmente por Éditions de la Martinière en el año 2004, tiene como tema principal lo que el autor denomina primera mundialización ibérica. Este fenómeno consiste en la interconexión inédita entre las 'cuatro partes del mundo' a las que se refiere el título de la obra (Europa, África, América y Asia, retomando la definición el cronista mestizo Chimalpahin) bajo el dominio de la monarquía católica, la unión de las coronas de España y Portugal entre 1580 y 1640. Esta unidad política que se pretendía universal, aseguró una conexión permanente entre los cuatro continentes, lograda a partir de la circulación continua de personas, bienes e ideas entre ellos. Dejando de lado la visión unidireccional y eurocéntrica propia del concepto de expansión ultramarina, el autor procura reconstruir las interacciones recíprocas dadas no sólo entre Europa y el resto del mundo, sino también entre Asia, América y África. El análisis de las lógicas de la globalización (la reproducción mimética de los hábitos y del sistema de pensamiento europeo en el resto del mundo), del mestizaje (la mezcla surgida del contacto intenso entre distintas sociedades e individuos) y la occidentalización (la transformación de los saberes y tradiciones europeas en patrimonio potencialmente universal) se aplica a un vasto conjunto de fuentes documentales e iconográficas surgidas de los cuatro continentes.

El libro se estructura en cuatro partes, a las que se suman un prólogo y un epílogo. La primera plantea que la visión de una modernidad definida sólo en función de procesos europeo-limitados (la Revolución Científica o el Absolutismo), soslaya la importancia capital que tuvo en su conformación el choque entre los distintos mundos y su novedosa conexión a nivel planetario. La segunda parte trata de las formas concretas en las que se establecieron las distintas conexiones intercontinentales/interculturales (mestizajes, migraciones, producción de informes y transmisión de noticias, circulación de libros y mercancías, transplante de instituciones civiles y eclesiásticas). La tercera, a su vez, se concentra en los hombres que articularon estos nexos: expertos que escriben extraoficialmente, miembros laicos y religiosos de las elites católicas que informan, evangelizan y gobiernan, mestizos que hacen equilibrio entre la herencia nativa y los horizontes planetarios de los que son expresión, todos sostienen los lazos planetarios que permiten el dominio de la monarquía católica. La cuarta y última parte se refiere a los mecanismos que sostuvieron la globalización del saber europeo y cómo este, reduplicado en ultramar, permaneció en cierto grado ajeno a las influencias de los mundos que se integraron en el seno de la monarquía católica. Así, el autor recupera la dimensión política y el desequilibrio de poder propio de toda situación colonial, que limita la dinámica de los mestizajes y deja intactos aspectos como la organización y validación del saber o las normas de distinción de la sociedad dominante.

La investigación se basa en el análisis de numerosas fuentes documentales e iconográficas producidas in situ, en las áreas de contacto entre los continentes desde mediados del siglo 
XVI hasta las primeras décadas del XVII. Sin duda, la variedad de las fuentes es uno de los puntos más interesantes del libro, en consonancia con la amplitud de miras geográficas, culturales y sociales que el tema analizado en él requiere. Recoge, además, un muy variado espectro géneros y registros, que van desde la poesía y el diálogo humanista hasta el rudo informe del soldado conquistador o de la más técnica investigación médico-farmacéutica, al diario de un mestizo.

El autor se beneficia de la mirada global con que la World History aborda las relaciones planetarias que se dan a raíz de la primera modernidad. A ella suma el concepto de connected histories enunciado por Sanjay Subrahmanyam, para explicar los mecanismos de anclaje que la movilización ibérica construye para sincronizar las distintas sociedades con las que entra en contacto. Este marco le permite proyectar sus reflexiones previas sobre los procesos de mestizaje y la construcción de una modernidad temprana ampliada a las relaciones europeo-americanas a un nivel de análisis planetario, en el que la monarquía católica sirve como unidad de análisis. Se plantea asimismo una perspectiva descentrada, que ve el mundo desde México, Manila o Cabo Verde, dejando de lado la lógica binaria de un centro/periferia, en favor de una imagen compuesta por múltiples centros y fronteras de contacto o middle-grounds; zonas en las cuales el mundo europeo choca y pone en relación comunidades e historias que habían transcurridos ajenas unas de otras.

Estas experiencias de confrontación, asimilación e imposición, en las que la agencia de los "otros" se torna insoslayable en la construcción de estas relaciones, se interpretan como parte esencial de la historia temprano moderna. América, África y Asia dejan de ser así un mero "margen" de la modernidad europea, para pasar a ser escenarios dinámicos y activos en la construcción de una inédita dimensión planetaria que dio sus rasgos a la primera modernidad.

Llama la atención, la casi nula mención que el autor hace de uno de los géneros literarios más populares de la época como lo fue la literatura de viajes, clave en la transmisión de las experiencias de ultramar a Europa. No obstante ello, la recuperación de las múltiples conexiones que articularon y dieron forma a la primera experiencia de mundialización, devuelve una imagen enriquecida del mundo temprano moderno. A lo largo del análisis, el autor rescata la historicidad específica del proceso, reivindicando a la Historia como una magnífica "caja de herramientas" con la cual reconstruir y reconectar fenómenos que los hechos posteriores, la lógica disciplinar, o las modas historiográficas velaron o dejaron de lado. Fenómenos de los cuales seguimos siendo testigos mientras continuamos transitando las encrucijadas que unen y acercan las distintas partes del mundo y los seres que lo habitan.

Maria Jualiana Gandini Museo Etnográfico J.B. Ambrosetti-

UBA-CONICET 